\author{
Ikuo TANABE ${ }^{1 *}$ \\ Yuhta YAMAGAMI ${ }^{1}$ \\ Hideo HOSHINO ${ }^{1}$
}

\title{
DEVELOPMENT OF A NEW HIGH-PRESSURE COOLING SYSTEM FOR MACHINING OF DIFFICULUT-TO-MACHINE MATERIALS
}

\begin{abstract}
In recent years, titanium alloys and nickel alloys have become eminent for making aeronautic and astronautic parts. Since both nickel and titanium alloys have a very small thermal conductivity, the being used tool will suffer from huge damage by heat generated during the grinding process. Therefore, there is a requirement for a durable tool with excellent cooling capacity. In this research, the technology regarding the new forced cooling using with highpressure coolant for machining difficult-to-machine material was developed and evaluated. A through-hole in the near the tip on the rake face of the turning tool is firstly machined by electrical discharge machining. Highpressure coolant was then supplied to the turning tool from the hole on the bottom of the tool. Several values of pressure were tried in many experiments. It is concluded from the results that; (1) a new forced cooling method in the form of drilling a hole at the tip of the tool from which supply high-pressure coolant, a tool temperature decrease and a tool-life prolongation could be achieved, (2) the technology could effectively cool near the tip of turning tool, (3) the chip was effectively broken by the high pressure, (4) It was confirmed that the tool cutting edge condition was stabilized, the surface roughness of the machined workpieces was improved, the tool hardness was maintained and the tool-life was prolonged due to the cooling effect of the devised tool.
\end{abstract}

\section{INTRODUCTION}

Recently, titanium alloys and nickel alloys are widely used as aircraft materials, and easy and high-precision machining methods for these materials are studied [1-3]. However, these two materials have low thermal conductivity, and most of the heat generated during processing is intensively conducted to the tool, which causes the vicinity of the tooltip to become hot and the hardness and mechanical strength of the tool experiment potential failure. Thus, an effective forced cooling technique against it is desired. Here, research is being carried out to forcibly cool the processing region with high efficiency by forced cooling by high-pressure coolant [4], on the tool rake surface [5], and there are also cases of research that the coolant has not reached the tip of the tool [5]. Consequently, a new forced cooling method for machining difficult-to-cut materials was proposed. Therefore, in this research, a new

\footnotetext{
${ }^{1}$ Nagaoka University of Technology, Department of Mechanical Engineering, Nagaoka, Japan

*E-mail: tanabeii@yahoo.co.jp https://doi.org/10.36897/jme/117776
} 
forced cooling technique to provide high-pressure coolant to the tip of a tool (insert) for turning to provide effective forced cooling was developed and evaluated. Specifically, by making a through-hole in the vicinity of the tooltip on the tool rake face and supplying highpressure coolant from the bottom of the through-hole toward the rake face, actively suppress the contact between the tool rake face and the chip, (1) suppression of frictional heat generation generated between the tool rake face and chips, (2) suppression of heat conduction to the tool of friction heat generated, and (3) highly efficient forced cooling near the tip of the tool. First, we studied functional and strength by using CAE for the specification of the hole drilled at the tooltip. Thereafter, the developed tool was mounted on a vertical lathe, the titanium alloy, which is a difficult-to-cut material, and the nickel alloy was turned as a workpiece, and the tool temperature measurement, the tool life measurement, the workpiece surface roughness measurement, chip geometry observations were conducted, respectively, and evaluated the industrial effectiveness of the new forced cooling system.

\section{EVALUATION OF MECHANICAL STRENGTH OF CUTTING TOOL INSERT USING FEM SIMULATION}

\subsection{METHOD EXPLANATION}

In this report, as shown in Fig. 1a, a through-hole is drilled in the vicinity of the insert tip of a turning tool, which is a turning tool, and high-pressure coolant is supplied from the bottom of the hole [6]. As a result, it is possible to constantly supply the coolant to the inside of the tool in the vicinity of the tooltip which becomes the highest temperature during cutting. As shown in Fig. 1b, by increasing the pressure of the coolant to be supplied, the chips on the rake face are pushed upward, the influence of cutting force on the tool rake face is reduced and it is thought that frictional heat generation can be suppressed by shortening the friction distance. At the same time, the area where frictional heat generation flows into the tool is also reduced.

a) Proposed forced cooling with-pressure coolant

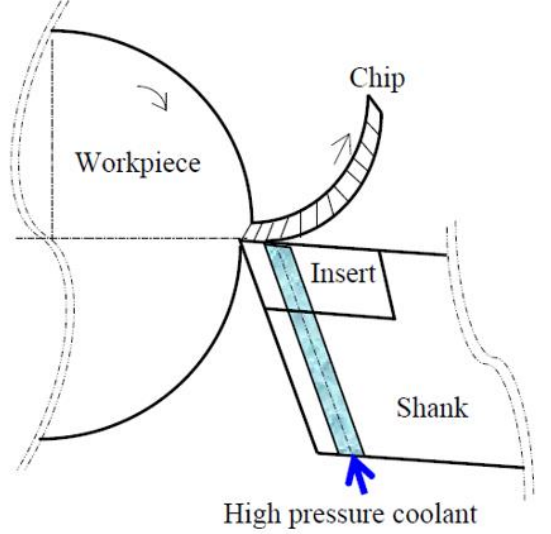

b) Generated chip behavior
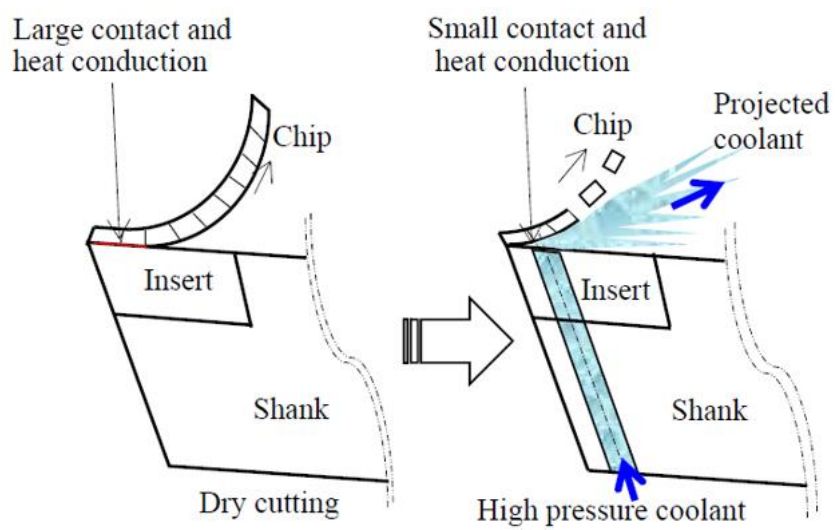

Fig. 1. Schematics of the proposed forced cooling method with high pressure coolant 
Furthermore, it is also possible to efficiently supply the coolant to the interface between the open chips and the tool rake face. Even though there is a similar technology known as Beyound BLAST [7] of KENNAMETAL Inc, it can be observed that in this report the proposed cooling method can push up chips directly from below through a high-pressure coolant that exceeds $8 \mathrm{MPa}$ during turning. At that time, it was difficult to measure the reduction of cutting force, so we confirmed from the subsequent FEM analysis result and estimated the validity from the tool temperature and the tool life test result.

\subsection{STRENGTH ANALYSIS}

In this section, the influence on the strength when holes are drilled near the tip of the tool is calculated using the finite element method analysis, and the specification of the hole provided at the tooltip is decided. The processing conditions and analysis conditions set in Table 1 are shown. The machining conditions were set so that the workpiece was turning machined in Inconel 718 and Ti6Al4V, which are represented as difficult cutting materials, under medium cutting conditions. Figure 2 shows the model of the insert for the finite element method (static analysis). The hole shape in the vicinity of the tip of the tool is made narrower than the width of the chip so as to push up the chip efficiently and it is made into a long hole shape to ensure the supply of a certain degree of coolant and the distance $X$ from the tooltip to the hole was used as an analysis parameter.

Table 1. Cutting conditions and FEM tool strength analysis conditions

\begin{tabular}{|c|c|c|c|c|}
\hline \multicolumn{5}{|c|}{ Cutting conditions } \\
\hline \multicolumn{2}{|c|}{$\begin{array}{l}\text { Cutting speed } \\
60 \mathrm{~m} / \mathrm{min}\end{array}$} & \multicolumn{2}{|c|}{$\begin{array}{l}\text { Feed speed } \\
0.8 \mathrm{~mm} / \mathrm{rev}\end{array}$} & $\begin{array}{l}\text { Depth of cut } \\
1.0 \mathrm{~mm}\end{array}$ \\
\hline \multicolumn{5}{|c|}{ Insert } \\
\hline \multicolumn{3}{|c|}{ Material: Coated carbide } & \multicolumn{2}{|c|}{ Rake angle: $-5^{\circ}$} \\
\hline \multicolumn{5}{|c|}{ FEM analysis conditions } \\
\hline \multicolumn{5}{|c|}{ Workpiece } \\
\hline \multicolumn{3}{|c|}{ Material } & Ti6Al4V & $\begin{array}{c}\text { Inconel71 } \\
8\end{array}$ \\
\hline \multicolumn{3}{|c|}{ Specific cutting force, $\mathrm{N} / \mathrm{mm}^{2}$} & 2060 & 2256 \\
\hline \multicolumn{3}{|c|}{ Cutting force, $\mathrm{N}$} & 1501 & 1644 \\
\hline \multicolumn{3}{|c|}{$\begin{array}{l}\text { Area of contact between } \\
\text { the insert and the chip mm }\end{array}$} & \multicolumn{2}{|c|}{$\begin{array}{c}L a=0.8 \\
X=1.0,2.0,3.0\end{array}$} \\
\hline \multirow{6}{*}{ Insert } & \multicolumn{2}{|c|}{ Type } & \multicolumn{2}{|c|}{ CNMA1204808 } \\
\hline & \multicolumn{2}{|c|}{ Corner radius } & \multicolumn{2}{|c|}{0.8} \\
\hline & \multicolumn{2}{|c|}{$\begin{array}{c}\text { Young's modulus, } \\
\text { GPa }\end{array}$} & \multicolumn{2}{|c|}{510} \\
\hline & \multicolumn{2}{|c|}{ Density, $\mathrm{kg} / \mathrm{m}^{3}$} & \multicolumn{2}{|c|}{8190} \\
\hline & \multicolumn{2}{|c|}{ Poisson's ratio } & \multicolumn{2}{|c|}{0.23} \\
\hline & \multicolumn{2}{|c|}{ Friction coefficient } & \multicolumn{2}{|c|}{0.3} \\
\hline
\end{tabular}

In the fixing method, the bottom of the insert was fixed. For the cutting load, simulate the round bar turning under the cutting conditions shown in Table 1, and give the main 
component forces $1644 \mathrm{~N}$ (Inconel 718) and $1501 \mathrm{~N}$ (Ti6Al4V) calculated from the processing conditions to the tooltip as the load [8]. Figure 3 shows Ti6Al4V, Fig. 4 shows Inconel 718 analysis results.

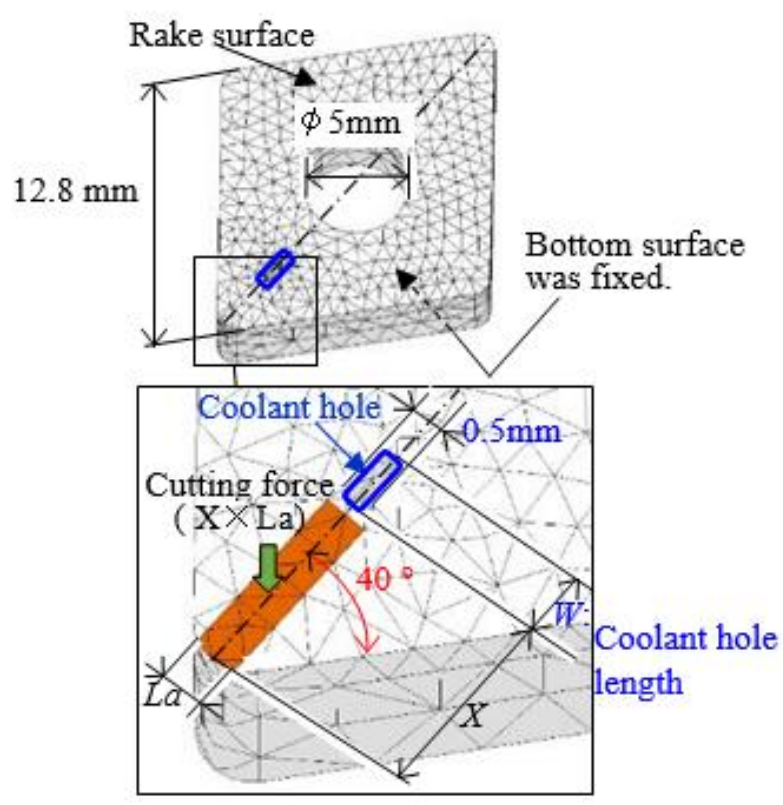

Fig. 2. Schematic view of the model for calculating the tool strength using FEM analysis

The stress distribution at the edge portion of the insert is shown in both figures. The position from the tip of the tool to the hole was $3 \mathrm{~mm}$ on the diagonal line and the area of the hole was $1.0 \mathrm{~mm}^{2}$, which was sufficiently within the allowable stress of $2.0 \mathrm{GPa}$. Also, this value is a size that allows chip chips on the rake face to be pushed up from high-pressure coolant from directly below (as described in detail below). In this way, we obtained the prospect that there would be no problem in terms of strength even if long holes with a width of $0.5 \mathrm{~mm}$ and an area of $1.0 \mathrm{~mm}^{2}$ were machined to $3.0 \mathrm{~mm}$ from the tooltip.

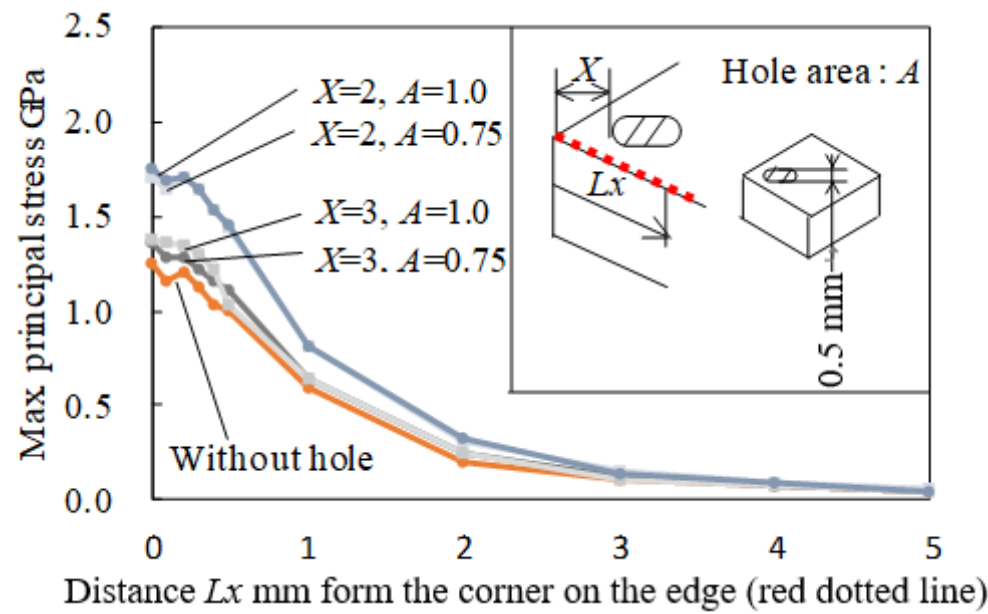

Fig. 3. Stress distribution (von Mises stress) on the edge of the insert using FEM structural analysis (Tool material: Ti-6Al-4V) 


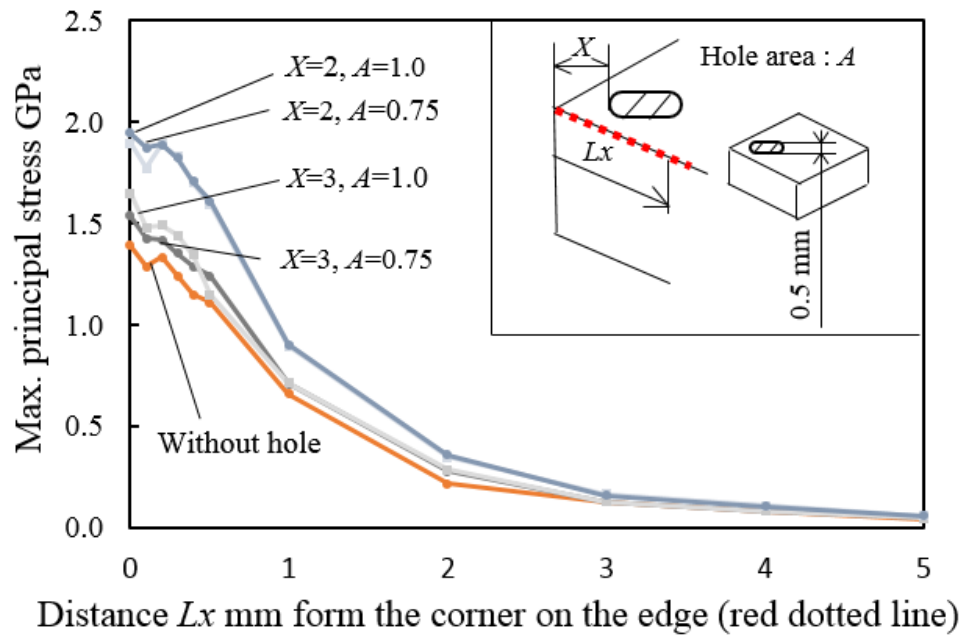

Fig. 4. Stress distribution (von Mises stress) on the edge of the insert using FEM structural analysis (Tool material: Inconel 718)

\subsection{DETERMINATION OF TOOL-CHIP CONTACT CONDITIONS [9]}

By supplying high-pressure coolant from the hole drilled at the tooltip and lifting the chip, (1) the frictional force of the chip decreases, the frictional heat generated between the tool rake face and the chip decreases, and (2) tool scooping Reduction of the amount of heat flowing into the tool as the contact area between the surface and the chip decreases, and (3) coolant can be injected into the interface between the tool rake face and the chip opening so that the cooling effect can be expected. Therefore, in this section, using the finite element method analysis, the degree of reduction of the contact area of the tool rake face and the chip by supplying the high pressure coolant from the hole drilled at the tooltip is analyzed by dynamic explicit software, and calculate the frictional heat generated at that time and the amount of inflow into the tool based on the cutting result [10] from the previous result and the cutting condition, then, based on the result, calculate with implicit solver software and conduct a thermal study on supplying high-pressure coolant from the hole drilled at the tooltip.

First, the degree of reduction of the contact area between the rake face and chip by supplying high-pressure coolant from the hole drilled at the tip of the tool is analyzed by dynamic explicit software LS-DYNA. Figure 5 shows the analysis model, and Table 2 shows the analysis conditions. It is the data based on several experiments. The calculation model used a model consisting of inserts and chips. The shape of the chip was determined from the processing conditions and placed on the insert. The chip move from the corner on the tip to inner direction of the tip. At that time, the chip push down the tip for the cutting force. When the chip came on the coolant hole outlet, the chip is pushed up by pressure the coolant jet. The behaviour is calculated by LS-DYNA.

Besides, to simulate chips discharged by machining, a chip model was prepared beforehand and flowed into the tool according to the machining, thereby simulating the behavior of the chip by machining. As for the processing conditions, medium cutting conditions of Inconel 718 and Ti6A14V were used as in Section 2.2. First, the discharge rate 
$(420 \mathrm{~mm} / \mathrm{s}$ ) calculated from the processing conditions was given to the chip as a boundary condition. Also, on the upper surface of the chip, the main component force generated by processing was given as the cutting force. The high-pressure coolant power was applied to the lower surface of the chip from the coolant hole $\left(X=3 \mathrm{~mm}, A=1.0 \mathrm{~mm}^{2}\right.$, width $\left.0.5 \mathrm{~mm}\right)$.

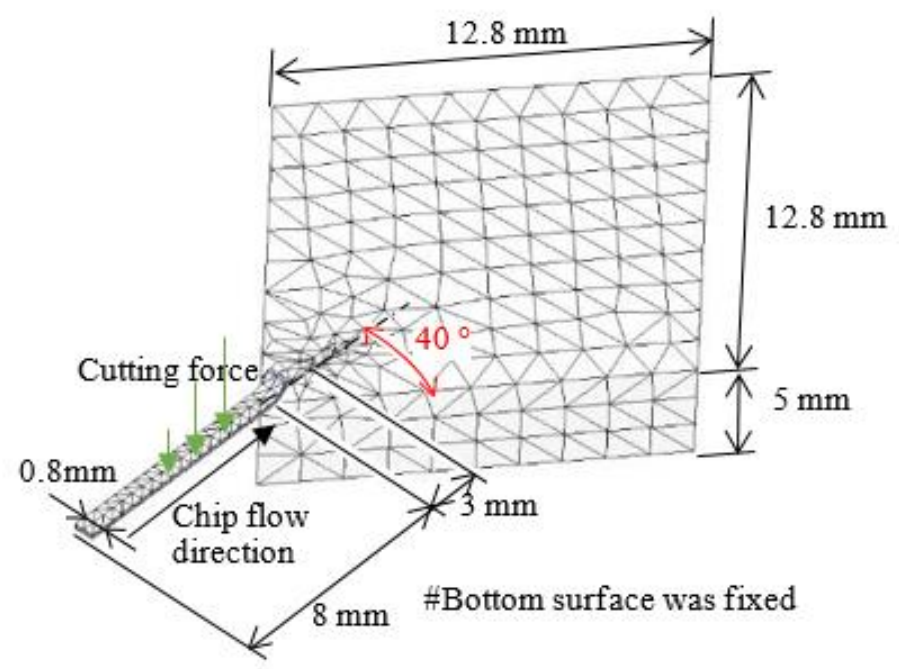

Fig. 5. Shematic view of the model for calculating the behaviour of the chip using FEM analysis

Table 2. FEM analysis condition for calculating the chip behaviour (OLS-DYNA)

\begin{tabular}{|c|c|c|}
\hline \multicolumn{2}{|c|}{ FEM analysis conditions } \\
\hline \multicolumn{3}{|c|}{ Used model : Johnson \& Cook model } \\
Ti6Al4V $\sigma=\left(1051+924 \varepsilon_{p}{ }^{0.52}\right)\left(1+0.0253 \ln \left(\varepsilon_{p} / \varepsilon_{0}\right)\left(1-T^{098}\right)\right.$ \\
Inconel 718 $\sigma=\left(1290+895 \varepsilon_{p}{ }^{0.526}\right)\left(1+0.016 \ln \left(\varepsilon_{p} / \varepsilon_{0}\right)\left(1-T^{1.55}\right)\right.$ \\
$\sigma$ : Stress, $\varepsilon_{\mathrm{p}}$ : Strain, $\varepsilon_{0}$ : Initial strain $(=0.03), T:$ Temperature
\end{tabular}


The cutting force and the force due to the high-pressure stream are such that even when the chip moves. To simulate the addition of, we set the position to change. This calculated how much chip can be lifted when the chips are subjected to a continuous flow. Here, Fig. 6 shows the analysis results of the behavior of chips on the tool rake face by supplying highpressure coolant from the hole drilled near the tooltip. It can be seen that the chip separates from the insert at the time when the chip passes over the coolant hole and is lifted by the force of the high-pressure stream. In the machining conditions shown in Table 2, the theoretical chip contact length was $4.5 \mathrm{~mm}$, whereas the high-pressure stream shortened the chip contact length to $2.5 \mathrm{~mm}$ for Inconel 718 and $2.4 \mathrm{~mm}$ for Ti6Al4V, thus, the friction distance between the chip and the insert is also shortened. Also, since it is possible to supply coolant to the part lifted by the force of the high-pressure stream, a large cooling effect can be expected. Fig. 7 shows the contact area between the tool rake face and the chip by supplying the high-pressure coolant from the hole drilled near the tip of the tool, and Fig. 8 shows the cutting force at that time.

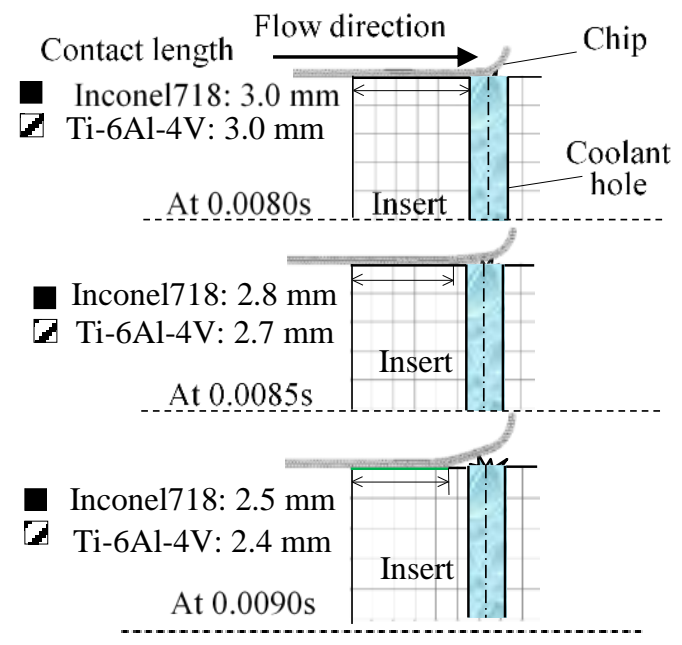

Fig. 6. Generated chip behaviour

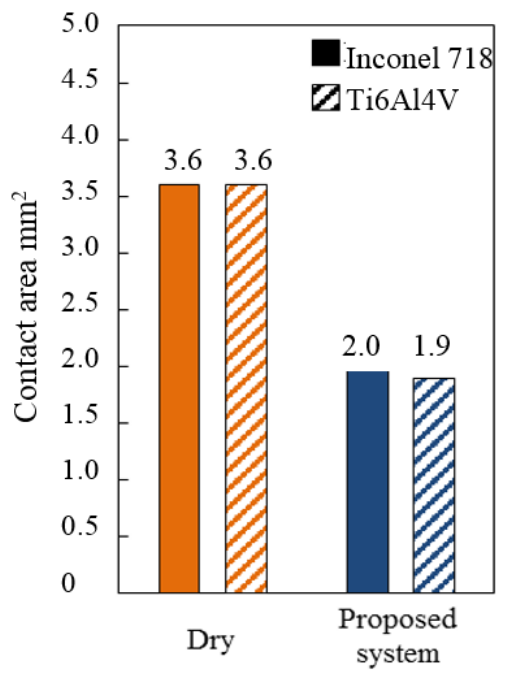

Fig. 7. Contact area between the insert and the chip

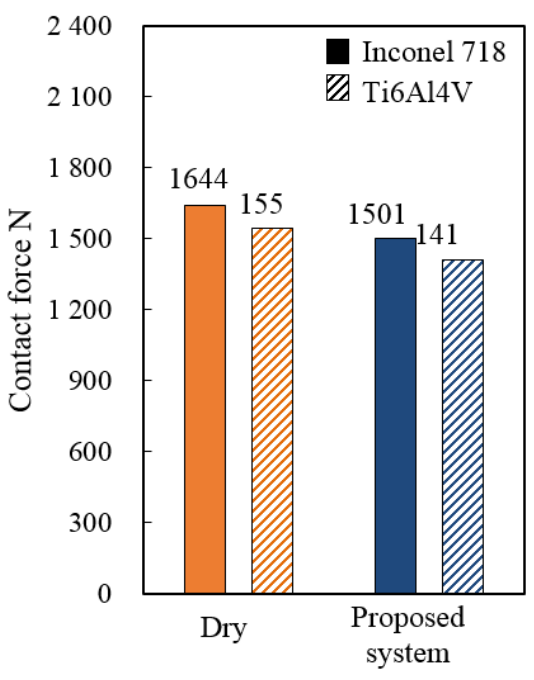

Fig. 8. Cutting force between the insert and the chip 
As shown in Fig. 7, the chip contact area in the absence of coolant is $3.6 \mathrm{~mm}^{2}$, whereas in the present method, as the chip contact length by raising the chip is shortened, the chip contact area when machining Inconel 718 was reduced to $2.0 \mathrm{~mm}^{2}$ (44\% reduction) and $1.9 \mathrm{~mm}^{2}$ (47\% reduction) when machining Ti6Al4V. Along with this, the amount of heat transfer to the tool is considered to be small. Further, as shown in Fig. 8, since the cutting force is reduced by the pushing up force by the high-pressure coolant flow, the frictional force generated on the tool rake face is reduced by $8 \%$ when Ti6Al4V, and the frictional heat generation is also reduced accordingly. When Ti6Al4V is dry processed under the processing conditions of Table 2, a heat quantity of $105 \mathrm{~W}$ flows into the tool (Takeyama, 1980). On the other hand, when Ti6Al4V is processed by this method, the heat transfer area decreases to $53 \%(=100-47 \%)$ and the cutting force decreases to $92 \%(=100-8 \%)$. As a result, it is considered that $52 \mathrm{~W}(=105 \mathrm{~W} \times 0.53 \times 0.92)$ which is $49 \%$ of the originally inflowing heat flows in.

Furthermore, the temperature of the tooltip by supplying the high-pressure coolant from the hole drilled near the tooltip is analyzed by the static implicit software SolidWorks. Figure 9 shows an analytical model composed of a shank and an insert, and Table 3 shows analysis conditions. The dry and wet cases without coolant holes were also calculated for comparison. Figure 10 shows the calculation results of the steady-state temperature distribution at the tip when a dry method with Ti6A14V, ordinary wet method (not highpressure coolant), this method is applied as an example in Fig. 10, and Fig. 11 shows the maximum temperature rise value Calculation results). By this method, the temperature rise at the tooltip can be effectively suppressed. When Ti6A14V is processed, when the wet processing is performed under the processing conditions of Table 2, the temperature rise of the tooltip is $707 \mathrm{~K}$. However, the amount of heat generation is suppressed by the highpressure flow using this method, and the coolant hole efficiently by cooling, it was possible to suppress the temperature rise of the tooltip at $64 \%(=449 / 707 \times 100)$ even under the same processing conditions as compared with wet processing. As a result, the softening of the tool can be suppressed, and tool life can be expected to be prolonged.

Table 3. Condition for calculating the tool top temperature using FEM analysis

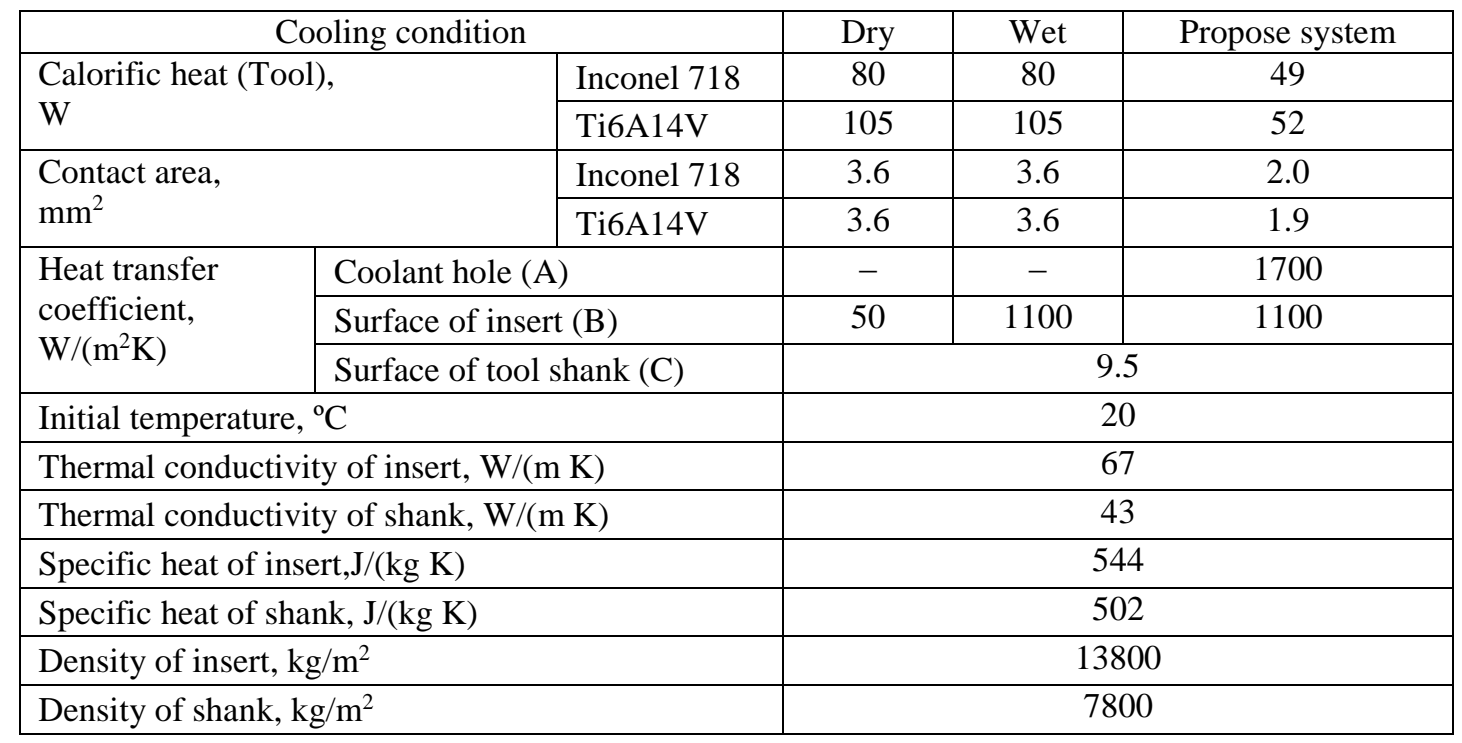




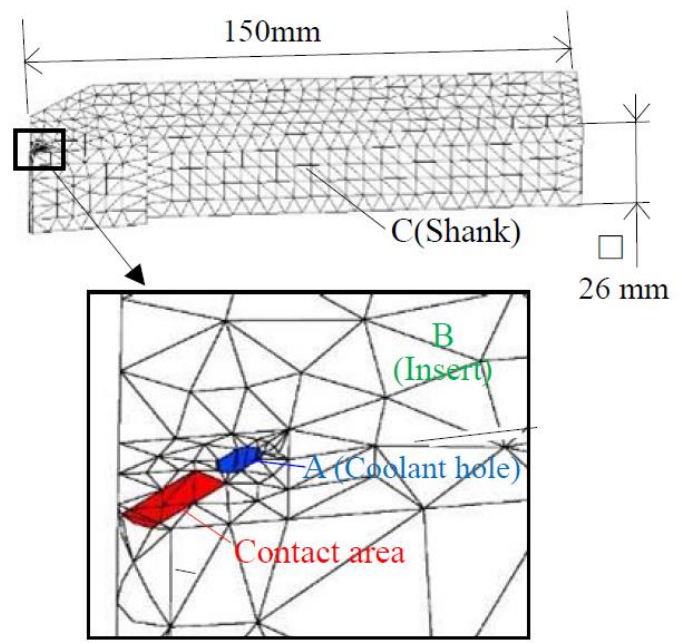

Fig. 9. Schematic view of the model for calculating the tool top temperature

(See Fig. 5. for the tip dimension)

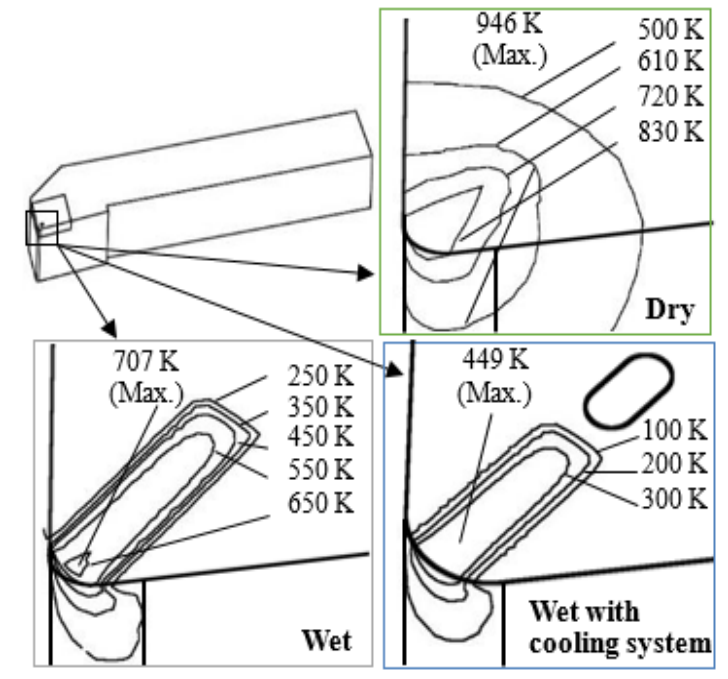

Fig. 10. Temperature change distribution on the tool top (Ti-6AI-4V)

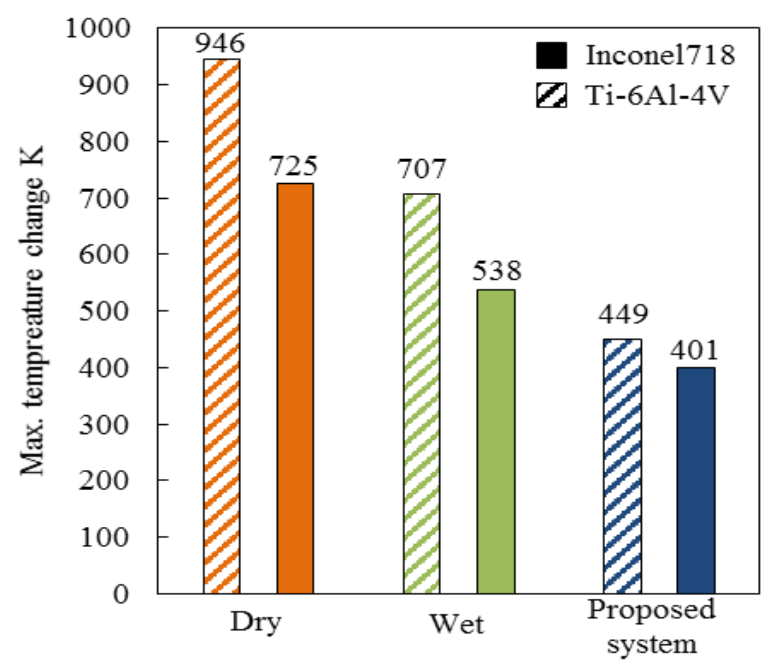

Fig. 11. Calculated results regarding the temperature change on the tool top using the proposed system

\section{EVALUATION OF PROPOSED FORCED COOLING METHOD}

\subsection{APPLICATION OF PROPOSED COOLING SYSTEM IN A VERTICAL LATHE}

Turning was carried out by mounting a new forced cooling device developed on a vertical lathe, and its cooling effect was evaluated. Figure 12 shows the photograph of the vertical lathe and processed part used in the experiment, and Table 4 shows the specifications and processing conditions of the vertical lathe. The aforementioned machining conditions, tool temperature, and tool life are measured for dry cutting, wet cutting with high-pressure coolant specification on the market, and wet cutting proposed in this report, and the cooling 
effect is evaluated. At this time, the pressure of the coolant to be supplied is used as an experimental parameter, and the condition with the most forced cooling effect is clarified. The tip shape of the tool used and the pressure of the coolant to be supplied are based on the results of the previous chapter.

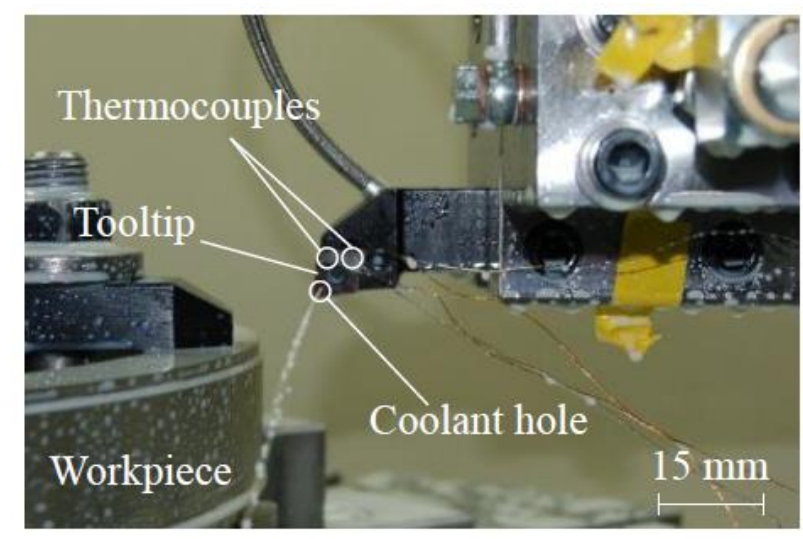

a). Tool with high pressure coolant

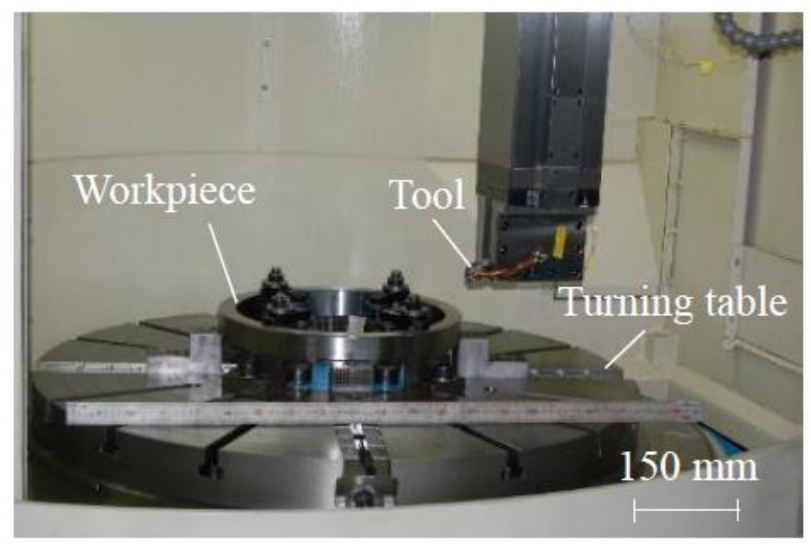

b). Schematic view of machining area

Fig. 12. Vertical lathe used in the experiment

Table 4. Specification of vertical lathe and cutting condition used in the experiment

\begin{tabular}{|c|c|c|c|}
\hline \multirow{9}{*}{ 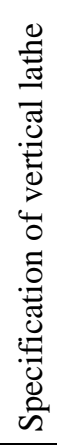 } & \multicolumn{2}{|c|}{ Table diameter } & $1100 \mathrm{~mm}$ \\
\hline & \multicolumn{2}{|c|}{ Max. turning diameter } & $1250 \mathrm{~mm}$ \\
\hline & \multicolumn{2}{|c|}{ Max. mass of workpiece } & $3000 \mathrm{~kg}$ \\
\hline & \multicolumn{2}{|c|}{ Max. cutting torque } & $10000 \mathrm{Nm}$ \\
\hline & \multicolumn{2}{|c|}{ Vertical travel of ram } & $800 \mathrm{~mm}$ \\
\hline & \multicolumn{2}{|c|}{ Max. feed speed } & $500 \mathrm{~mm} / \mathrm{rev}$ \\
\hline & \multicolumn{2}{|c|}{ Main motor } & $30 \mathrm{~kW}$ \\
\hline & \multicolumn{2}{|c|}{ Max. height of machine } & $3790 \mathrm{~mm}$ \\
\hline & \multicolumn{2}{|c|}{ Floor space } & $3955 \times 3840 \mathrm{~mm}$ \\
\hline \multirow{8}{*}{ 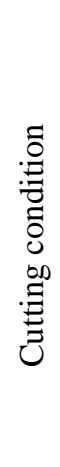 } & \multicolumn{2}{|c|}{ Work piece material } & $\begin{array}{l}\text { Ti-6Al-4V, } \\
\text { Inconel } 718\end{array}$ \\
\hline & \multicolumn{2}{|c|}{ Tip material } & Coated carbide \\
\hline & \multicolumn{2}{|c|}{ Depth of cut } & $1.0 \mathrm{~mm}$ \\
\hline & \multicolumn{2}{|c|}{ Feed speed } & $0.8 \mathrm{~mm} / \mathrm{rev}$ \\
\hline & \multicolumn{2}{|c|}{ Cutting speed } & $60 \mathrm{~m} / \mathrm{min}$ \\
\hline & \multirow{3}{*}{ 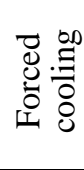 } & Cooling fluid & Emulsion \\
\hline & & Fluid pressure & $1,8,20 \mathrm{MPa}$ \\
\hline & & Quantity of flow & $0.5 \mathrm{l} / \mathrm{min}$ \\
\hline
\end{tabular}

This processing condition is a condition capable of reliably pushing up chips from just under while maintaining the strength of the tool. Also, in the next report, for the high productivity of difficult-to-cut material processing, strong alkaline water [11] containing microbubbles [12], we are considering superimposing on the method of this report, and at that 
time the feed speed is set at $0.8 \mathrm{~mm} / \mathrm{min}$, which is larger. Calculating from the cutting theory (Takeyama, 1980) under this processing condition shows that the heat input to the tool is $150 \mathrm{~W}$ and the tooltip temperature is $2271^{\circ} \mathrm{C}$ by dry cutting, whereas if only the feed speed is changed to $0.2 \mathrm{~mm} / \mathrm{min}$, the tool, the tooltip temperature is $1192^{\circ} \mathrm{C}$. In consideration of the heat resistance of the tool, it is considered effective to divert this method even under the mentioned conditions.

\subsection{TOOL TEMPERATURE EVALUATION}

Here, the workpiece of Ti6Al4V was first cut under the cutting conditions of Table 4, and the rise in tool temperature at that time was measured. It shows the temperature course in the vicinity of the tip of the cutting tool (point A). In the case of wet cutting with commercially available high-pressure coolant specification, the supplied high-pressure coolant was directly applied to the thermocouple, making it difficult to measure the temperature rise. Also, in the proposed method, the forced cooling effect is large, and the temperature rise at point $\mathrm{A}$ is about $5^{\circ} \mathrm{C}$. This is thought to be because the inner surface of the hole was forcibly cooled efficiently by heat transfer with the coolant by providing a hole near the tip of the tool. Figure 13b shows the result of using the experimental value of Fig. 13a together with FEM analysis. These are extrapolated from the temperature course of two points (point $\mathrm{A}$ and point B) near the tip of the cutting tool by FEM analysis.

In the case of wet cutting with the high-pressure coolant specification on the market, it was difficult to extrapolate the tooltip temperature because the temperature change could not be measured as shown in Fig. 13a. In the proposed method, by increasing the pressure of the high-pressure coolant to be supplied, the forced cooling effect is gradually increased and the rise of the tooltip temperature is also suppressed.

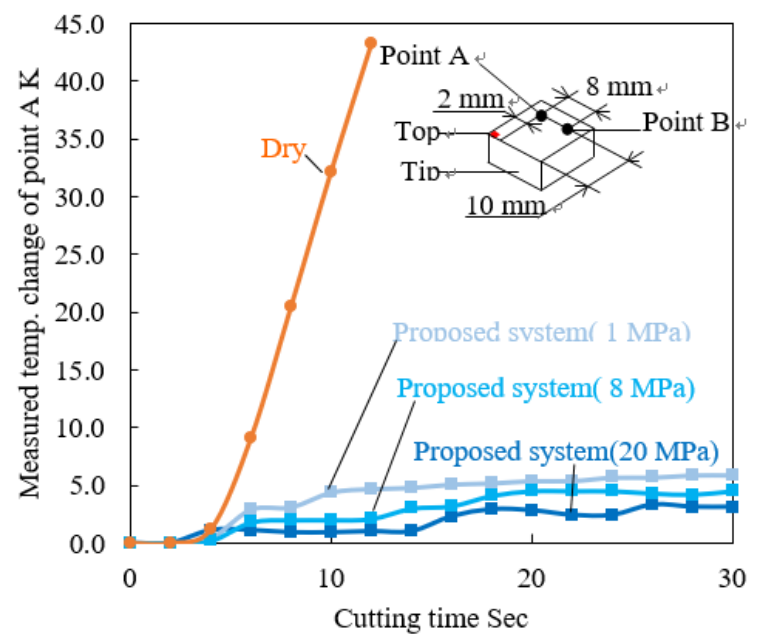

a) Measured temperatures around tip of bit

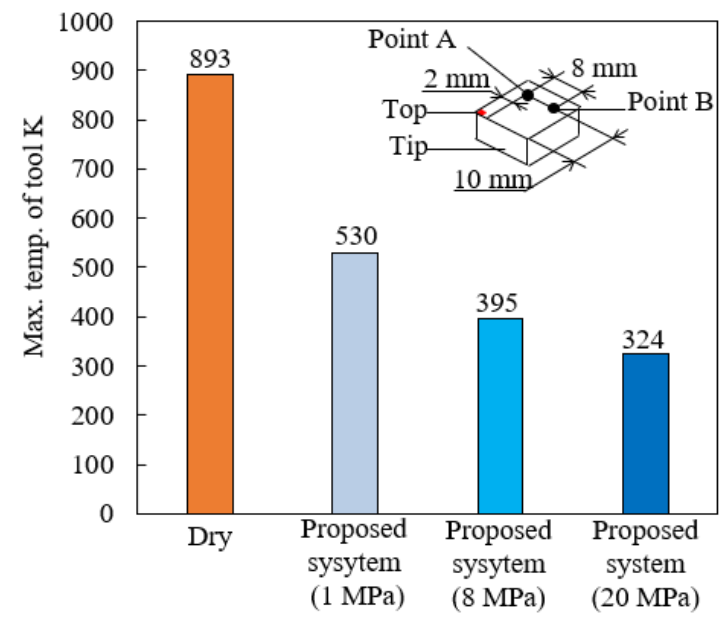

b) Influence of pressure

Fig. 13. Temperature change on the tool using high pressure coolant (In the case of Ti-6Al-4V) 


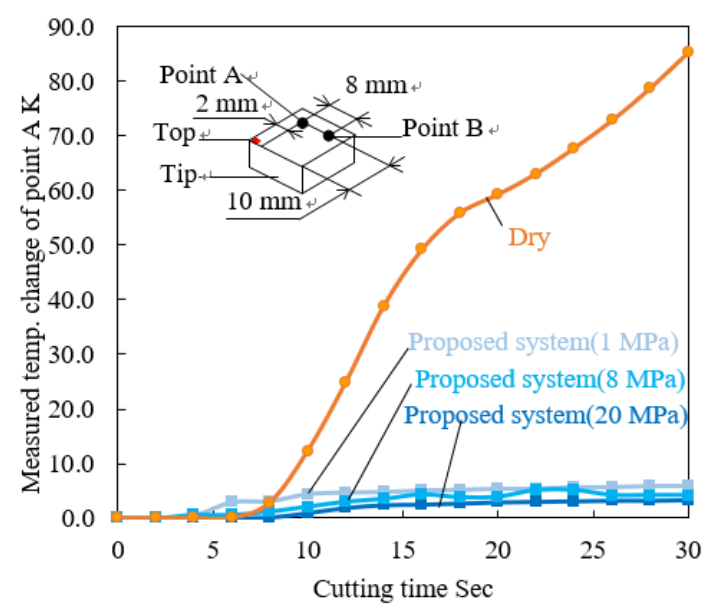

a) Measured temperatures around tip of bit

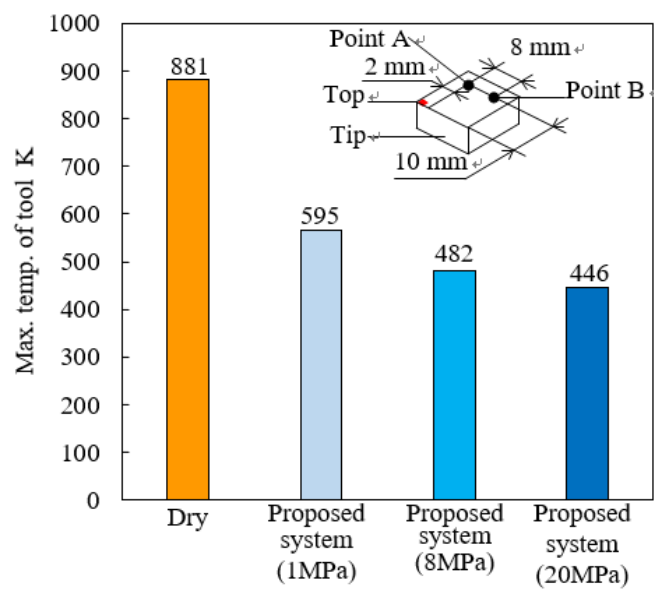

b) Influence of pressure

Fig. 14. Temperature change on the tool using high pressure coolant (In the case of Inconel 718)

Subsequently, the workpiece of Inconel718 was cut under the cutting conditions of Table 4, and the rise in tool temperature was measured and the result is shown in Fig. 14. The same result as in the case of the previous workpiece Ti6Al4V was obtained, and from the tool temperature, the forced cooling effect of the proposed method was confirmed.

\subsection{TOOL-LIFE EVALUATION}

The tool life was evaluated with the same cutting conditions (Table 4) as in the previous section and evaluated the proposed forced cooling method. As for the parameter, three types of dry cutting, wet cutting with specifications of commercial high-pressure coolant and the wet cutting proposed in this report were adopted. First, Fig. 15 shows the results of the tool life test when the workpiece is Ti6Al4V. In the case of wet cutting (20 MPa) proposed in this report, the tool life has increased by about 10.2 times compared to dry cutting.

In addition, the tool life has increased by about 2.7 times compared to wet cutting ( $8 \mathrm{MPa}$ ) of the high-pressure coolant specification on the market. This is considered to be the result of the wet cutting proposed in this report that the high efficiency forced cooling effect of the coolant suppressed the decrease in the hardness of the tool and maintained the tool rigidity [13]. Figure 16 shows a photograph near the tooltip immediately after judging the tool life when the workpiece is Ti6Al4V. From the photograph, it can be seen that the wet cutting proposed in this report is less influential to the tool. As a result of observation using a tool microscope, the occurrence of cracks and cracks near the tip hole was not observed.

Moreover, Fig. 17 shows the results of the tool life test in the case where the workpiece is Inconel718, and Fig. 18 shows the photograph in the vicinity of the tooltip immediately after judging the tool life in the case where the workpiece is Inconel 718. In the case where the workpiece is Inconel 718, it is more commercially available than the proposed method of wet processing $(8 \mathrm{MPa})$ of the high-pressure coolant specification of, the tool life was longer. This means that the chip of Inconel718 became a shear-type rather than a flow type, and small chips were produced. As a result, it is thought that the life span was long because 
the chip became an obstacle for forced cooling, and it became possible to supply the coolant to the vicinity of the tooltip even in the conventional wet type, and it became possible to effectively supply the coolant.

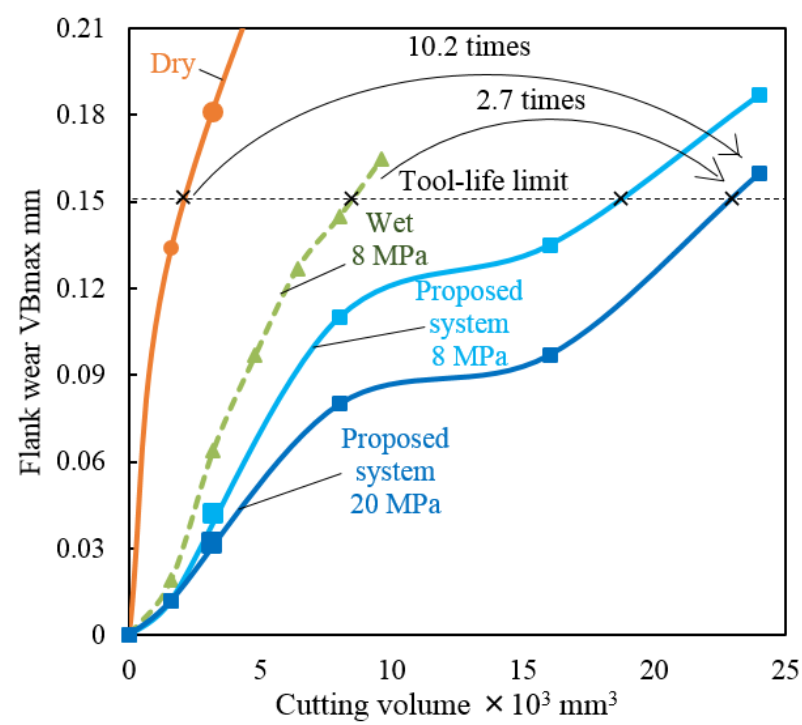

Fig. 15. Experimental results of tool-life test (In the case of Ti-6Al-4V)

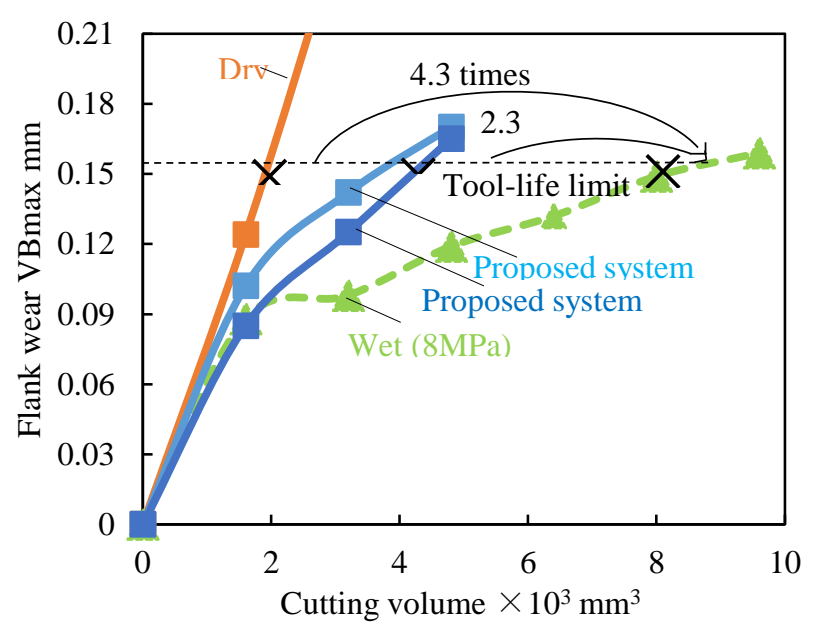

Fig. 17. Experimental results of tool-life test (In the case of Inconel 718)

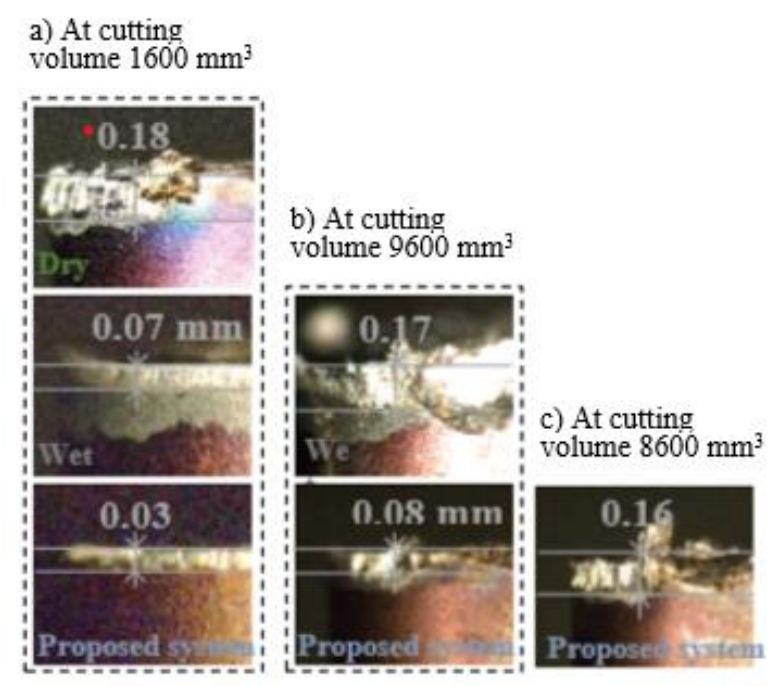

Fig. 16. Photographs of each tool at their tool life limit (Wet: Proposed system: $20 \mathrm{MPa}$ ) (In the case of Ti-6Al-4V)

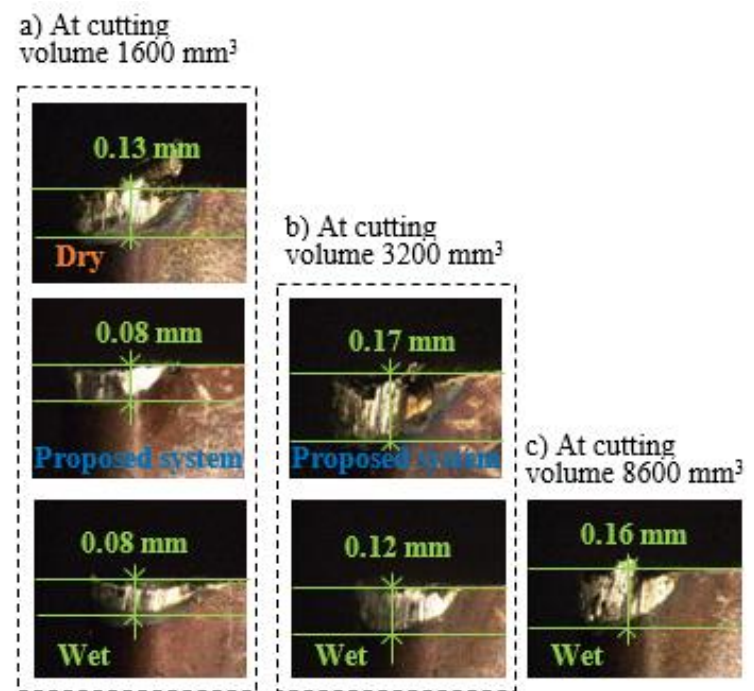

Fig. 18. Photographs of each tool at their tool life limit (Wet: $8 \mathrm{MPa}$, Proposed system: 20MPa) (In the case of Inconel 718)

\subsection{RELATIONSHIP BETWEEN COOLANT PRESSURE AND CHIP GEOMETRY}

Finally, a simple consideration of the chip shape was made. The parameters of the experiment were dry cutting, wet cutting with commercially available high-pressure coolant specifications, and wet cutting proposed in this report. Using the vertical lathe of Table 3 , 
cutting was carried out under the processing conditions of Table 4. Table 5 shows photographs of the segmented chips during each processing when the workpiece is Ti6Al4V. In any of the cuttings, the surface of the chip that was in contact with the tool rake surface was metallic luster, and it was not possible to investigate the effect of processing temperature due to discoloration. In wet cutting with high-pressure coolant specifications on the market, the original chip breaker function was working effectively. Even with the wet cutting proposed in this report, when the supply coolant pressure reached $20 \mathrm{MPa}$, a sufficient chip breaker function was demonstrated. In the wet cutting (20 MPa) proposed in this report, intermittent depressions are observed on the surface of the chip that was in contact with the tool rake surface. This is thought to be due to deformation caused by the high-pressure coolant supplied from the coolant hole during cutting effectively lifting the chips.

Table 5. Photographs of each chip (In the case of Ti-6Al-4V)

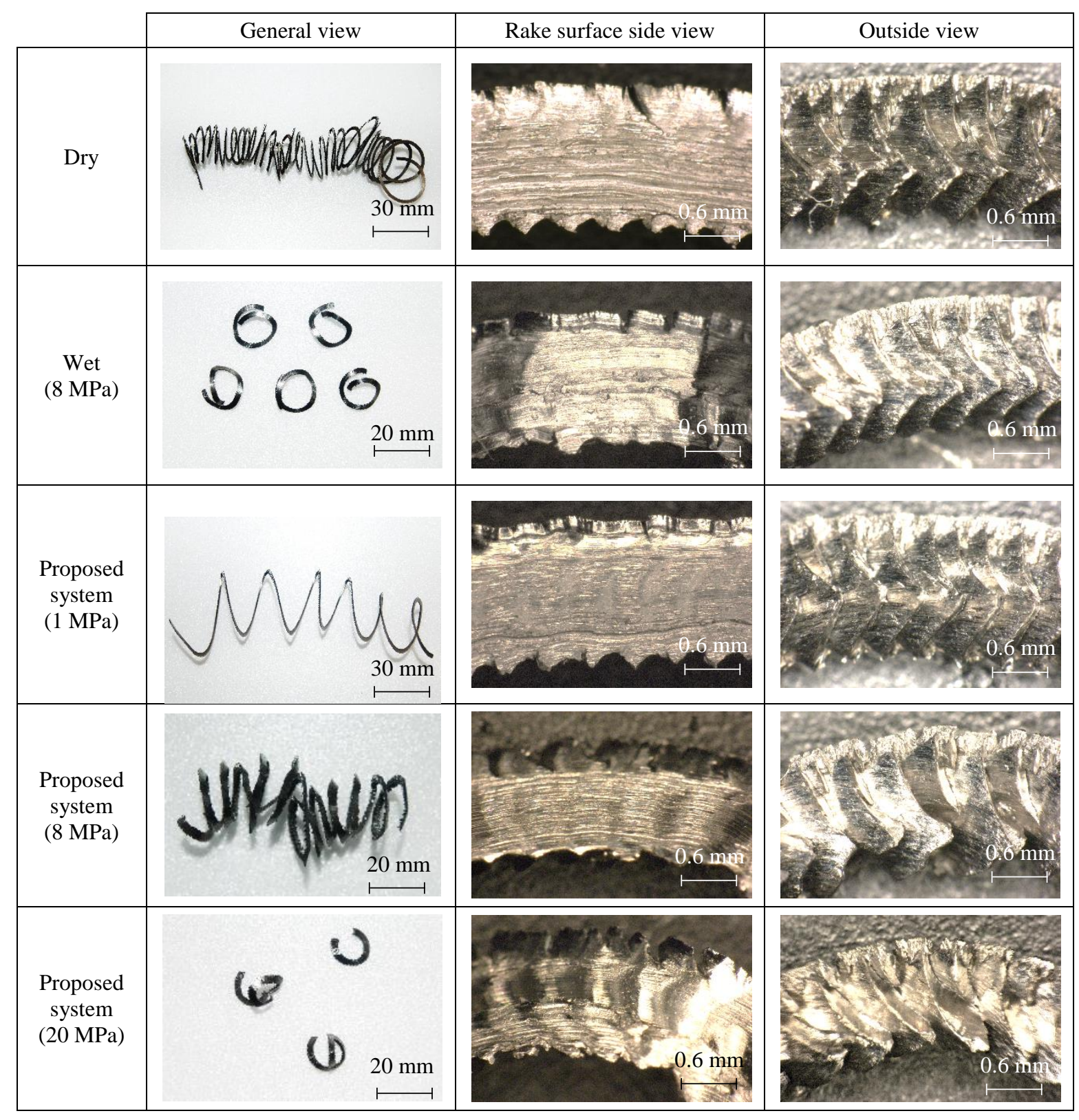


Table 6. Photographs of each chip (In the case of Inconel 718

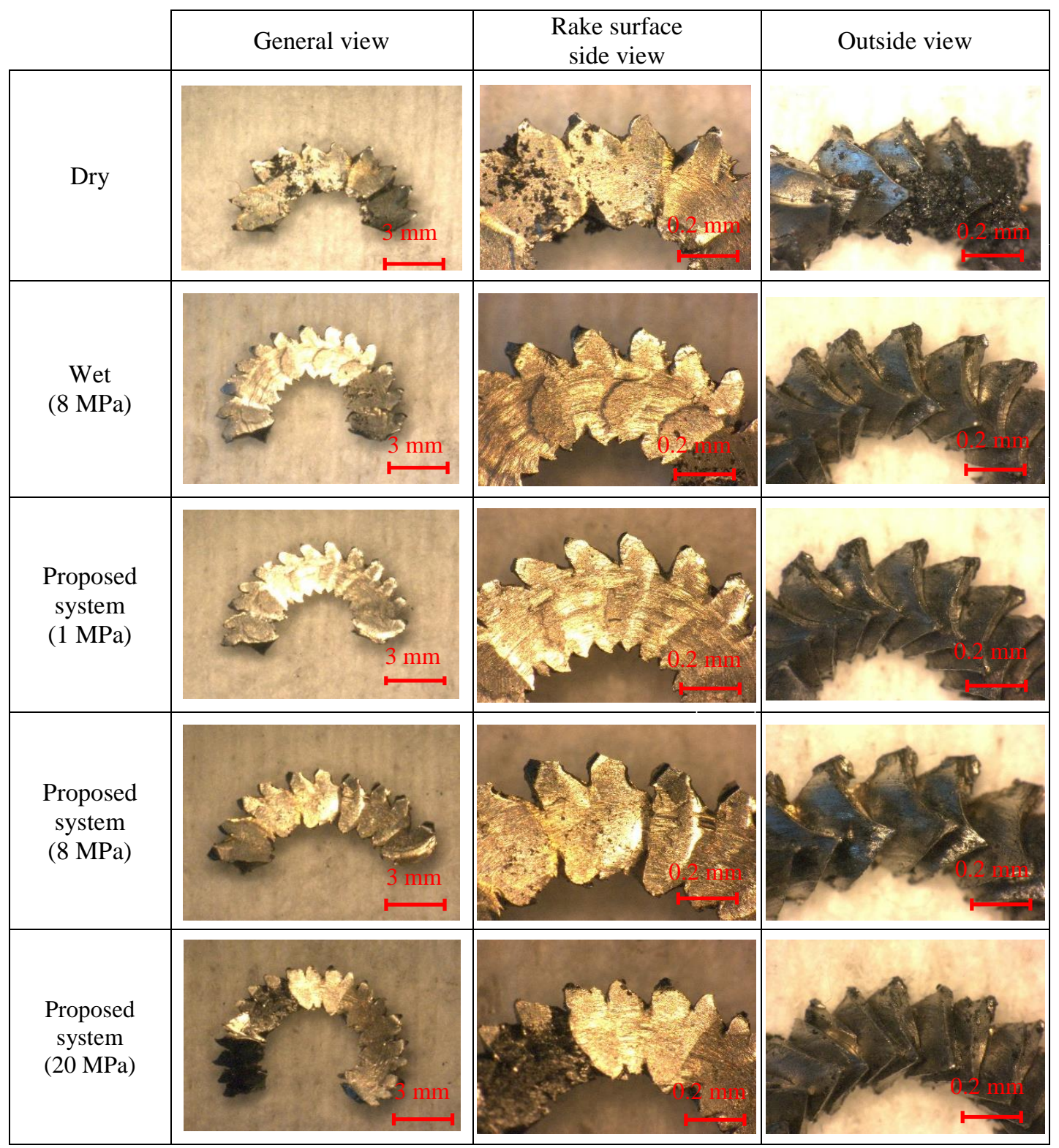

Table 6 shows photographs of the segmented chips during each processing when the workpiece is Inconel 718. Even in dry processing, shear-type chips occurred in which small chips occur consecutively. Therefore, it is considered that the chip is not divided by this method. Because such chips were generated, we believe that the chips did not reach the coolant holes provided for this method and could not lift chips.

In this way, when the workpiece is Ti6Al4V, in the wet cutting proposed in this report, the high-pressure coolant used has not only a highly efficient forced cooling function but also a chip breaker function at the same time. Furthermore, the coolant ejected from the hole drilled in the vicinity of the tip of the tool has the function of forcibly cooling the cut chips, which is also effective for suppressing the thermal deformation of the used machine tool, which is considered to be very effective. 


\section{CONCLUSIONS}

I. It was concluded that by drilling a hole at the tip of the tool from which supply highpressure coolant, a tool temperature decrease and a tool-life prolongation could be achieved, here, the inner surface of the hole is forcibly cooled ad the coolant can be supplied between the rake face and the tool. Consequently, heat generation during the machining of difficult-to-machine materials can be suppressed to a certain extent.

II. Coolant can be supplied between the rake face and the tool by devising a high-pressure coolant supply method.

\section{REFERENCES}

[1] KITAGAWA T., KUBO A., MAEKAWA K., 1997, Temperature and wear of cutting tools in high-speed machining of Inconel 718 and Ti-6Al-6V-2Sn, Wear, 202/2, 142-148.

[2] SOE Y.H., TANABE I., IYAMA T., HOANG T.B., 2010, Tool Technology to Reduce Cutting Heat Generation and Its Influences, Journal of Machine Engineering, 10/3, 51-56.

[3] SAKAMOTO H., TANABE I. TAKAHASHI S., 2015, Development of software for calculation of best condition using Taguchi methods and its evaluation, Journal of machine Engineering, 15/2, 44-54.

[4] OHMORI S., KATOH T., MAEDA T., UENO H., 2013, Effect on chip-breaking in cutting to supply high pressure coolant, Memoirs of Akashi National College of Technology, 55, 7-12, (in Japanese).

[5] TANIGAWA Y., MIYAZAWA S., 1997, Improvement of tool life by jet supplied cutting fluid, Journal of the Japan Society of Precision Engineering, 63/4, 540-544, (in Japanese).

[6] TANABE I., MINH T.H., YOSHII K., 2000, Turning with environment-friendly cooling method using water evaporation: 1st report, cooling effect of water evaporation and its applicability to tool tip cooling, Transactions of the Japan Society of Mechanical Engineers, Series C, 66/643, 1026-1030, (in Japanese).

[7] KENNAMETAL Beyound BLAST, 2013, Metalworking Master Catalogue.

[8] TAKEYAMA H., 1980, Cutting process, Maruzen Inc., Los Angeles, CA, USA, 15-25, 30, 35-42, 64, (in Japanese).

[9] WIT GRZESIK, 2017, Advanced Machining Processes of Metallic Materials, Elsevier, Chapter 7.

[10] TANABE I., MINH T.H., 2001, Cutting with an environment-friendly cooling method using water evaporation: Establishment of this cooling model and calculation of the suitable supply quantity of water, Transactions of the Japan Society of Mechanical Engineers, Series C, 67/664, 4011-4016, (in Japanese).

[11] CRUZ J.R.D., TANABE I., SAKAGUCHI N., 2014, Development of immersed machine tool and machining in the strong alkaline water for reduction of $\mathrm{CO}_{2}$, Journal of Machine Engineering, 14/3, 71-82.

[12] SHIMOHIRA S., 1995, Material science for corrosion and its protection, AGNE Gijutsu Center, 30-32, 255-257, 287-288.

[13] WAKAO K., FUJIWARA J., MIYAMOTO T., 2009, Cutting temperature and tool wear progress in turning of cemented carbide, Proceedings of JSPE Semestrial Meeting 2009, JSPE Autumn Conference, 119-120, (in Japanese). 